\title{
Development of a Sensorless Estimation Algorithm of the Injection Timing and Rate for an HSDI Common-Rail Injector*
}

\begin{abstract}
Kihoon $\mathrm{NAM}^{* *}$, Maru YOON***, Seungbum PARK ${ }^{* *}$ and Myoungho SUNWOO***
The performance of a common-rail fuel injection system and its effects on diesel engine combustion are strongly influenced by the injector characteristics. The injection timing and the injection rate of the common-rail injection system are important factors for combustion control and pollutant formation mechanism during the engine operation. This paper presents a dynamic model of the common-rail injector for high speed direct injection (HSDI) diesel engines and introduces a methodology for estimating the injection timing and the injection rate of the injector. The numerical simulation and the experimental results show that the proposed sliding mode observer (SMO) can effectively estimate the injection timing and the injection rate of the common-rail injector.
\end{abstract}

Key Words: HSDI (High Speed Direct Injection), Common-Rail Injection System, SMO (Sliding Mode Observer)

\section{Introduction}

A lot of attention is being paid to the common-rail fuel injection system as a next generation technology to enhance fuel economy and reduce pollutant emissions in diesel vehicles and to satisfy stringent emission regulations in the US and other countries. Accordingly, extensive research has been performed to maximize the overall performance of diesel vehicles with the common-rail injection system in terms of low pollution and high efficiency and capacity ${ }^{(1)-(6)}$.

The main advantages of the system are as follows. First, the injection pressure can be generated independently of the engine speed and injection fuel quantity because the generation of pressure and the injection of fuel are completely decoupled from each other. Second, particulate matter (PM) can be reduced through good mixture formation by high-pressure fuel injection. Third, the ambient noise and nitrogen-oxidized substances can be reduced by the pilot and post injection. Finally, unlike the mechanical fuel injection system, it is possible to control the injection timing and rate electronically with the common-rail fuel injection system.

* Received 1st December, 2003 (No. 03-5146)

** Powertrain R\&D Center, Hyundai Motor Company, 7721 Jangduk-dong, Whasung-si, Gyunggi-do 445-706, Korea

*** Dept. of Automotive Engineering, Hanyang University, 17 Haengdang-dong, Seongdong-gu, Seoul 133-791, Korea. E-mail: msunwoo@hanyang.ac.kr
The aim of this paper is to describe the modeling process of a common-rail injection system and to propose a design methodology for the estimations of the injection timing and the injection rate of the common-rail injection system. To this end, the remainder of the paper is organized as follows. Section 2 introduces a common-rail injection system including its structure and operating principle. A mathematical model of the common-rail injection system is derived in section 3 . In section 4, a sliding mode observer (SMO) is designed for the estimation of state variables of the injection system. Experimental results are discussed in section 5 through a comparison study on the simulation results and experimental data. Finally, a conclusion is drawn in section 6 .

\section{Nomenclature}

$\beta_{f}, \beta_{f h}, \beta_{f c}$ : Bulk modulus of elasticity in the control, hollow, and sac chamber, respectively $\left[\mathrm{N} / \mathrm{m}^{2}\right]$

$\Delta P_{i}$ : Pressure difference between the armature chamber and atmosphere $\left[\mathrm{N} / \mathrm{m}^{2}\right]$

$\lambda:$ Coil flux linkage $[\mathrm{Wb}]$

$\theta:$ Installation angle of injector [rad]

$\rho:$ Fuel density $\left[\mathrm{kg} / \mathrm{m}^{3}\right]$

$A_{i}, A_{o}$ : Inlet and outlet orifice area of control chamber, respectively $\left[\mathrm{m}^{2}\right]$

$A_{a}, A_{p}$ : Armature and servo piston area, respectively $\left[\mathrm{m}^{2}\right]$

$A_{h}:$ Injection hole area $\left[\mathrm{m}^{2}\right]$

$A_{h o}$ : Outlet orifice area of hollow chamber $\left[\mathrm{m}^{2}\right]$

$A_{n}, A_{n s}$ : Area in both ends of the needle valve [ $\left.\mathrm{m}^{2}\right]$ 
$A_{s}:$ Flow area $\left[\mathrm{m}^{2}\right]$

$b_{a}, b_{n}$ : Damping coefficient in armature and needle valve, respectively $[\mathrm{Ns} / \mathrm{m}]$

$C_{d i}, C_{d o}$ : Inlet and outlet flow coefficient of control chamber, respectively [-]

$C_{d h i}, C_{d h o}$ : Inlet and outlet flow coefficient of hollow chamber, respectively [-]

$C_{d s i}, C_{d s o}$ : Inlet and outlet flow coefficient of sac chamber, respectively [-]

$F_{\text {mag }}:$ Magnetic force [N]

$F_{s r}:$ Return spring force $[\mathrm{N}]$

$F_{s v}:$ Valve spring force [N]

$g:$ Gravitational acceleration $\left[\mathrm{m} / \mathrm{s}^{2}\right]$

$i$ : Operating current [A]

$k_{n}, k_{r}, k_{v}$ : Nozzle, return, and valve spring constant [N/m] $m_{a}, m_{n}, m_{p}$ : Mass of armature, needle valve, and servo piston, respectively [kg]

$P_{c}, P_{h}, P_{s}$ : Control, hollow, and sac chamber pressure, respectively [bar]

$P_{\text {rail }}, P_{c y l}, P_{\text {return }}:$ Common-rail, cylinder, and atmospheric pressure, respectively $\left[\mathrm{N} / \mathrm{m}^{2}\right]$

$Q_{h i}, Q_{h o}$ : Fuel flow rate into/out from the hollow chamber $\left[\mathrm{m}^{3} / \mathrm{sec}\right]$

$Q_{i}, Q_{o}$ : Fuel flow rate into/out from the control chamber $\left[\mathrm{m}^{3} / \mathrm{sec}\right]$

$Q_{s i}, Q_{s o}$ : Fuel flow rate into/out from the sac chamber $\left[\mathrm{m}^{3} / \mathrm{sec}\right]$

$R$ : Coil resistance $[\Omega]$

$V$ : Input voltage [V]

$V_{c}, V_{h}, V_{s}$ : Control, hollow, and sac chamber volume, respectively $\left[\mathrm{m}^{3}\right]$

$V_{c 0}$ : Initial volume of control chamber volume $\left[\mathrm{m}^{3}\right]$

$V_{s 0}:$ Sac chamber volume without needle valve $\left[\mathrm{m}^{3}\right]$

$\hat{x}, \tilde{x}$ : Estimated state variable and state estimation er- ror, respectively

$x_{a}, x_{n}$ : Armature and needle valve displacement, respectively $[\mathrm{m}]$

$x_{n 0}, x_{n f}$ : Initial setting and free length of needle valve spring, respectively [m]

EOI : End of injection

SOI : Start of injection

\section{Common-Rail Fuel Injection System}

\subsection{Fuel injection system structure}

A common-rail fuel injection system (see Fig. 1) is mainly comprised of three components ${ }^{(2),(3)}$ : the low pressure stage, the high pressure stage, and the electronic control unit (ECU). The low pressure stage incorporates the fuel tank with a pre-filter, a pre-supply pump, a fuel filter, and low pressure fuel lines. The high pressure stage of the fuel system in common-rail installation consists of the high pressure pump with a pressure control valve, high pressure fuel lines, and the common-rail. Again, the common-rail consists of a rail pressure sensor, a pressure limiting valve, a flow limiter, injectors, and fuel return lines. Fuel is stored in the common-rail under the specified pressure ready for injection.

The amount of fuel being injected is regulated by the injector driver, and the start of injection (SOI) and the injection pressure are calculated by the ECU. The ECU then triggers the solenoid valves so that the injector at each cylinder injects accordingly.

\subsection{Operating principle of common-rail injector}

The operating mode of the common-rail injector is as follows. Upon feeding an electric pulse of a given duration to the solenoid, the solenoid valve is retracted from its resting position, and the pressure in the hydraulic control assembly (control chamber) drops very rapidly, while the

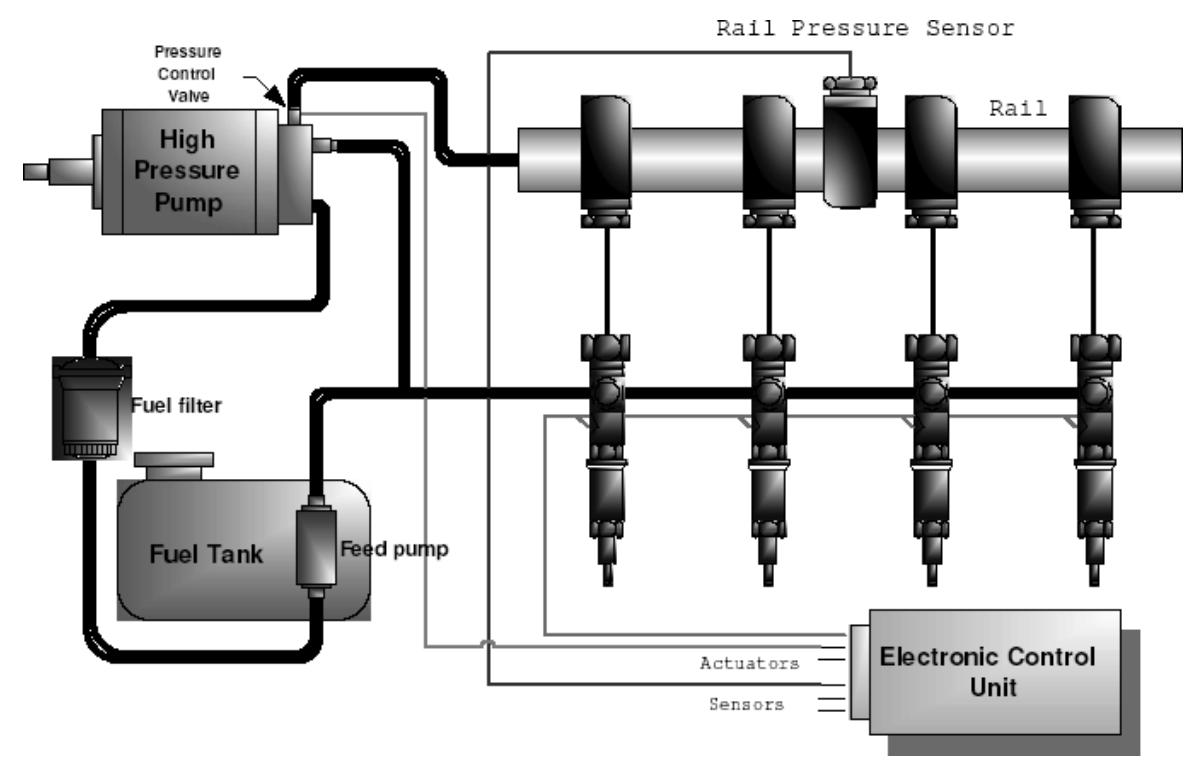

Fig. 1 Common-rail fuel injection system 


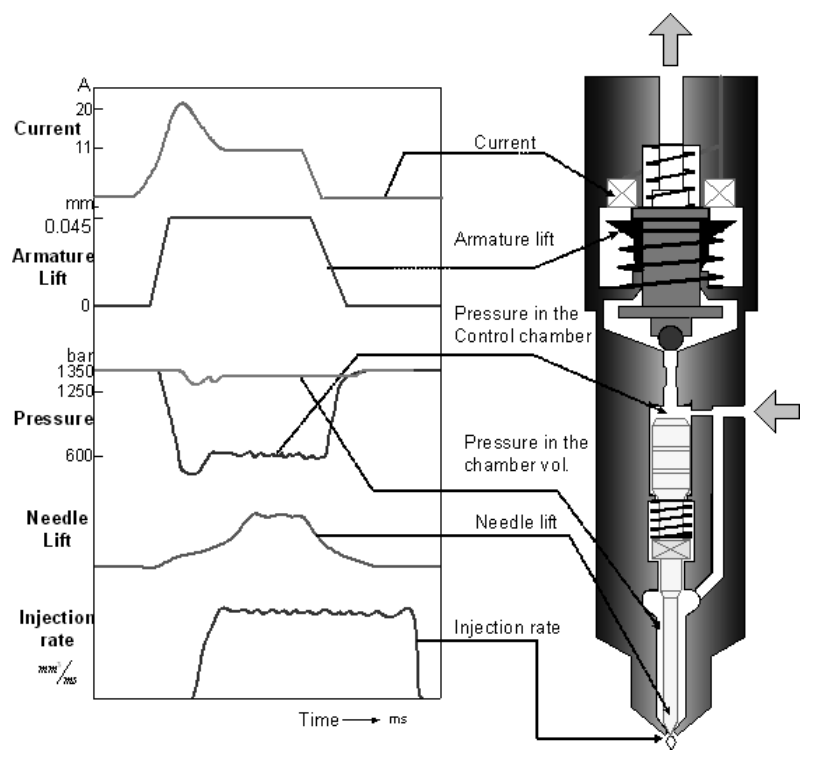

Fig. 2 Operation of common-rail injector

pressure in the sac chamber is maintained. The pressure difference between the control and sac chambers causes the needle valve to open up and the fuel in the sac chamber to be injected through the nozzle tip. An interruption of the electric pulse to the solenoid returns the solenoid valve to its original position, and the outlet orifice of the control chamber is closed. Accordingly, the pressure in the control chamber shifts the needle valve to its closed position and the injection process is terminated. A simple schematic diagram of the injector can be shown in Fig. 2 .

\section{Nonlinear Mathematical Model of Common-Rail Injector}

This section presents a mathematical model of the common-rail injector for predicting the dynamic response of the injector. The basic assumptions for modeling of the common-rail injector is as follows ${ }^{(4),(5)}$ :

- The pulsation of the supply pressure is neglected.

- The pressure of the control chamber is equal to the supply pressure.

- The return pressure is equal to the atmospheric pressure.

- The friction of the movable part is ignored.

- Fuel is compressible.

- The cylinder pressure is regular.

The overall model is comprised of several models of electrical and mechanical components: solenoid, armature, hollow chamber, pressure control chamber, servo piston, needle valve and sac chamber. In the following sections the modeling processes are described in brief.

\section{1 Solenoid}

The solenoid voltage is represented by the Kirchhoff's voltage law as shown in Eq. (1).

$$
V=i R+\frac{d \lambda}{d t}
$$

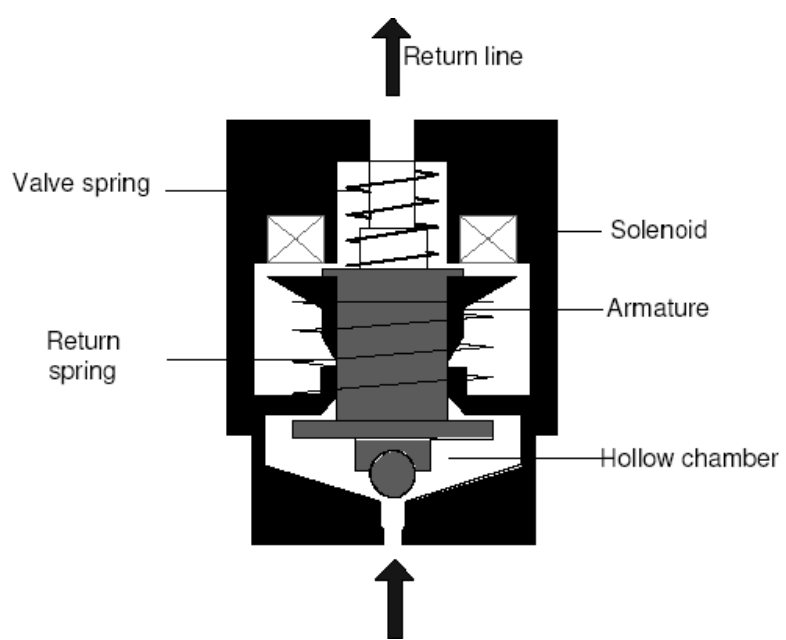

Fig. 3 Operation of an armature in the common-rail injector

$$
\begin{aligned}
& =i R+\frac{\partial \lambda\left(i, x_{a}\right)}{\partial i} \cdot \frac{d i}{d t}+\frac{\partial \lambda\left(i, x_{a}\right)}{\partial x_{a}} \cdot \frac{d x_{a}}{d t} \\
& =i R+L\left(i, x_{a}\right) \frac{d i}{d t}+E\left(i, x_{a}\right) \frac{d x_{a}}{d t}
\end{aligned}
$$

where

$$
L\left(i, x_{a}\right)=\frac{\partial \lambda\left(i, x_{a}\right)}{\partial i} \quad \text { and } E\left(i, x_{a}\right)=\frac{\partial \lambda\left(i, x_{a}\right)}{\partial x_{a}}
$$

In Eq. (1), $\lambda$ represents the coil flux linkage and is the function of current and armature displacement. The first, second and third terms on the right hand side of Eq. (1) are the voltage drop by resistance, the induced voltage by the current change and the back EMF (electromotive force), respectively. Consequently, the rate of change of the current of the solenoid has the following form:

$$
\frac{d i}{d t}=\frac{V-i R-E\left(i, x_{a}\right) \frac{d x_{a}}{d t}}{L\left(i, x_{a}\right)}
$$

\subsection{Armature}

The armature is operated by the sucking force of the solenoid and controls the pressure of the control chamber (See Fig. 3). The behavior of armature is described as follows:

$$
m_{a} \ddot{x}_{a}=A_{a} \Delta P_{i}+F_{m a g}-m_{a} g \cos \theta-F_{s v}-F_{s r}-b_{a} \dot{x}_{a}
$$

The magnetic force of the solenoid, $F_{\text {mag }}$, is experimentally determined in a 3-D look-up table with solenoid current and armature lift as inputs.

\subsection{Hollow chamber}

The fuel discharged from an outlet orifice returns to the fuel tank through a hollow chamber. At this time, the pressure of the hollow chamber is changed by the fuel flow out from the pressure control chamber. The behavior of flow in the hollow chamber is represented in terms of the following equations:

$$
\dot{P}_{h}=\frac{\beta_{f h}}{V_{h}}\left(Q_{h i}-Q_{h o}\right)
$$




$$
\begin{aligned}
& Q_{h i}=C_{d h i} \cdot A_{o} \cdot \sqrt{\frac{2}{\rho}\left|P_{c}-P_{h}\right|} \\
& Q_{h o}=C_{d h o} \cdot A_{h o} \cdot \sqrt{\frac{2}{\rho}\left|P_{h}-P_{\text {return }}\right|}
\end{aligned}
$$

where the volume of a hollow chamber is considered to be constant, because it is hardly changed.

\section{4 Pressure control chamber}

The structure of a pressure control chamber is shown in Fig. 4. From the simplified schematic diagram, we obtain the following equations describing the behavior of the pressure in the control chamber:

$$
\begin{aligned}
& \dot{P}_{c}=\frac{\beta_{f}}{V_{c}}\left(Q_{i}-Q_{o}-\dot{V}_{c}\right) \\
& Q_{i}=C_{d i} \cdot A_{i} \cdot \sqrt{\frac{2}{\rho}\left|P_{\text {rail }}-P_{c}\right|} \\
& Q_{o}=C_{d o} \cdot A_{o} \cdot \sqrt{\frac{2}{\rho}\left|P_{c}-P_{h}\right|}
\end{aligned}
$$

where

$$
V_{c}=V_{c 0}-A_{p} x_{p} \quad \text { and } \quad \dot{V}_{c}=-A_{p} \dot{x}_{p}
$$

\subsection{Servo piston and needle valve}

The motion of the servo piston combined with the needle valve is described by a second-order ordinary differential equation as follows.

$$
\begin{aligned}
& \left(m_{p}+m_{n}\right) \ddot{x}_{n}=-k_{n}\left(x_{n f}-x_{n 0}\right)-k_{n} x_{n}-A_{p} P_{c}-b_{n} \dot{x}_{n} \\
& \quad+P_{\text {rail }}\left(A_{n}-A_{n s}\right)-\left(m_{p}+m_{n}\right) g \cos \theta
\end{aligned}
$$

The terms on the right hand side in the equation represent the initial spring force, the spring force by the needle displacement, the pressure force of the control chamber, the force by damping effect, the force by rail pressure, and the gravitational force, respectively.

\subsection{Sac chamber}

The sac chamber pressure is changed by the action of the needle valve displacement. The fuel is supplied to the cylinder by changing the sac chamber pressure. The behavior of the pressure in the sac chamber is represented as follows ${ }^{(6)}$ (see Fig. 5):

$$
\begin{aligned}
& \dot{P}_{s}=\frac{\beta_{f s}}{V_{s}} \cdot\left(Q_{s i}-Q_{s o}-\dot{V}_{s}\right) \\
& Q_{s i}=C_{d s i} \cdot A_{s} \cdot \sqrt{\frac{2}{\rho}\left(P_{r a i l}-P_{s}\right)} \\
& Q_{s o}=C_{d s o} \cdot A_{h} \cdot \sqrt{\frac{2}{\rho}\left(P_{s}-P_{c y l}\right)}
\end{aligned}
$$

where

$$
V_{s}=V_{s 0}-V_{\text {needle }} \quad \text { and } \quad \dot{V}_{s}=-\dot{V}_{\text {needle }}
$$

The $V_{\text {needle }}$ is the volume occupied by the needle valve in the sac chamber, and is calculated from the geometric

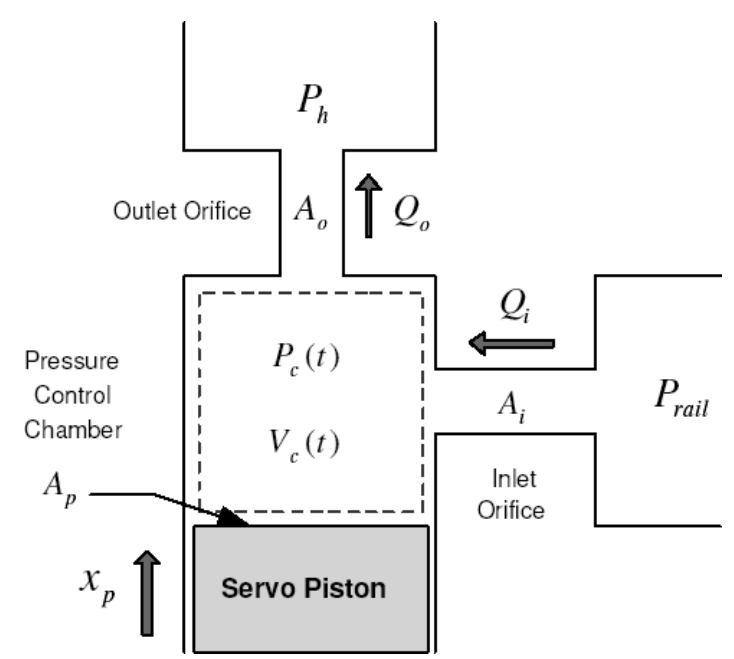

Fig. 4 Schematic diagram of pressure control chamber

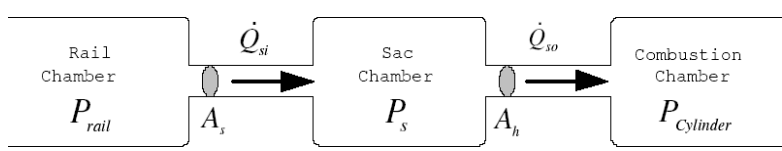

Fig. 5 Simplified version of sac chamber model

shape of the needle valve and the sac chamber as a function of the needle lift.

\subsection{State equation}

As a result, the mathematical model for an HSDI common-rail injector is represented by following state equations:

$\dot{\boldsymbol{x}}=f(\boldsymbol{x}, u)$

$f(x, u)$

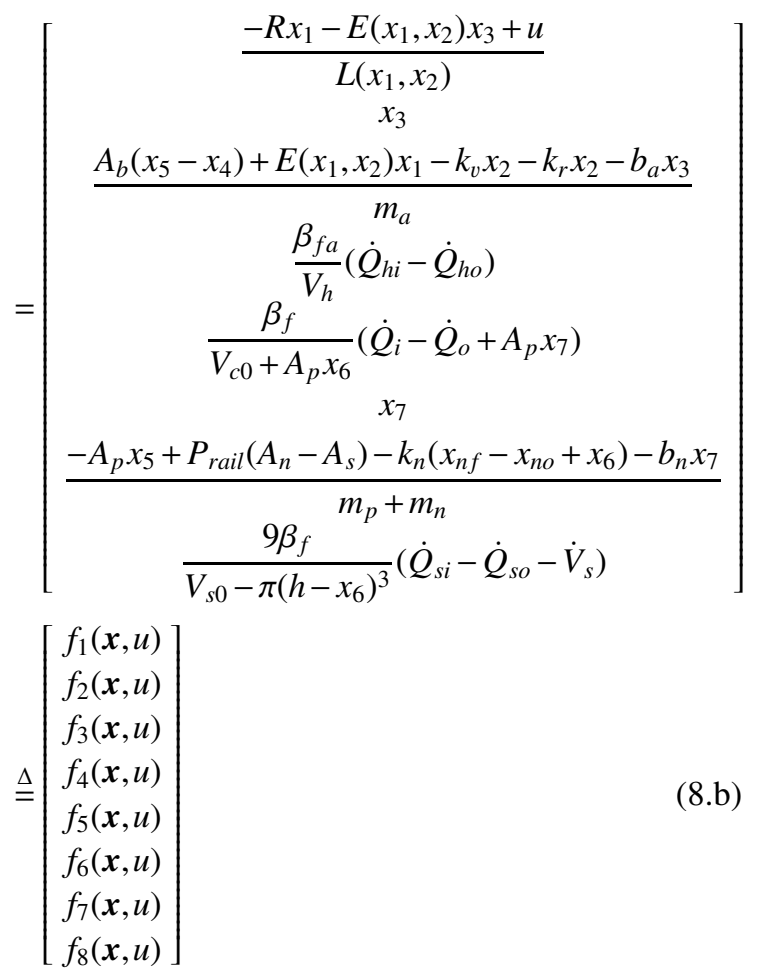

In above equations, $u$ is the input of the system, 
i.e., the solenoid voltage and the state vector is $\boldsymbol{x}=$ $\left[\begin{array}{llllllll}x_{1} & x_{2} & x_{3} & x_{4} & x_{5} & x_{6} & x_{7} & x_{8}\end{array}\right]^{T} ; x_{1}=$ solenoid current, $x_{2}=$ armature displacement, $x_{3}=$ armature velocity, $x_{4}=$ hollow chamber pressure, $x_{5}=$ control chamber pressure, $x_{6}=$ needle lift, $x_{7}=$ needle velocity, $x_{8}=$ sac chamber pressure.

\subsection{Validation}

In this section, we present the simulation and the experimental study to validate the injector model derived in this paper. First of all, in order to evaluate the accuracy of the proposed model, simulation results and the experimental data are compared over a spectrum of operating points. The simulation and the experiment study of the common-rail injection system have been conducted by changing the rail pressure and the injection duration. The input signal to the injection model is the solenoid execution voltage and the output is the execution current. During the tests, the following data were measured: solenoid voltage and current, and injection rate. The injection rate was measured via an commercial injection rate meter from ONOSOKI ${ }^{\circledR}$. The simulation is performed with MATLAB $^{\circledR}$ on a Pentium III ${ }^{\circledR}$ personal computer, and the Euler method is adapted for integration.

Figure 6 compares the simulated and measured
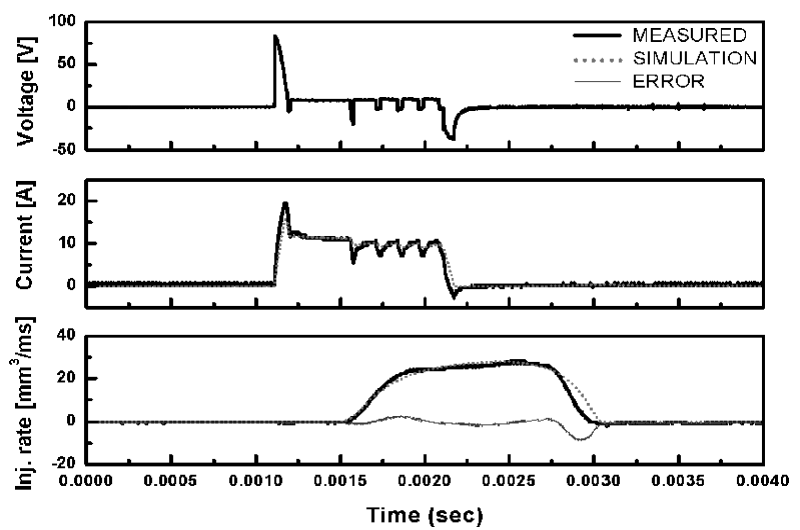

(a) Injection duration $=1.0 \mathrm{~ms}$, rail pressure $=1100 \mathrm{bar}$
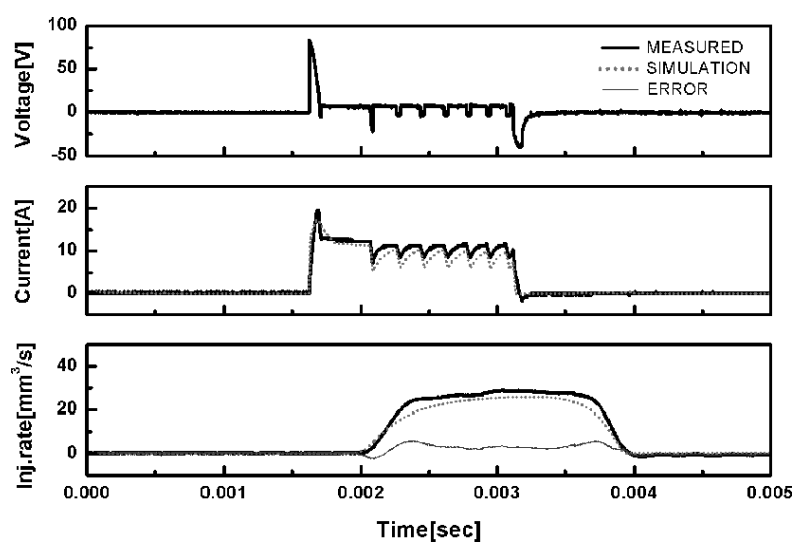

(b) Injection duration $=1.5 \mathrm{~ms}$, rail pressure $=1200 \mathrm{bar}$

Fig. 6 Comparison between the simulation and experimental data results. For the presentation purposes, two sets of the injection duration and rail pressure are selected: $1.0 \mathrm{~ms} / 1100$ bar and $1.5 \mathrm{~ms} / 1200$ bar. Although not presented here, a good agreement between simulation and experimental results is shown for all operating conditions. However, some differences have been found in the solenoid current and injection rate profiles. For example, the slopes of the experimental solenoid current and injection rate are slightly different from those of the simulation results. The differences may come from the model error caused by assumptions, measurement error, ignored dynamics, and so on. It should be noted that the proposed model is sufficiently accurate for use in designing the observer discussed in the next sections.

\section{Observer Design}

\subsection{State observer}

Most modern control theories require information about state variables and demand sensors that can measure the physical quantities related to the state variables. However measuring all the states would be expensive and complex. In addition, there might be no applicable sensors to conduct such measurements. Therefore, a novel method is needed and an observer has been proposed as one of the solutions. The observer is a mathematical algorithm which estimates the state variables using the output of the system and can be applied to sensorless controls.

\subsection{Injection timing and rate observer design}

There have been many studies regarding the development of the state estimation of nonlinear systems based on the Luenberger observer that is applicable to linear systems (for instance, Ref. (7)). In this study, we consider the SMO to take full advantage of its capability to deal with modeling uncertainties ${ }^{(8)-(10)}$.

For a single-input single-output (SISO) nonlinear system, the SMO has the following form (particularly for the fuel injection system considered in this study):

$$
\begin{aligned}
& \dot{\hat{x}}_{1}(t)=f_{1}(\hat{\boldsymbol{x}}, u)+k_{1} \operatorname{sign}\left(x_{1}-\hat{x}_{1}\right) \\
& \dot{\hat{x}}_{2}(t)=f_{2}(\hat{\boldsymbol{x}}, u)+k_{2} \operatorname{sign}\left(x_{1}-\hat{x}_{1}\right) \\
& \quad \vdots \\
& \dot{\hat{x}}_{8}(t)=f_{8}(\hat{\boldsymbol{x}}, u)+k_{8} \operatorname{sign}\left(x_{1}-\hat{x}_{1}\right)
\end{aligned}
$$

A state estimation error is defined as:

$\tilde{\boldsymbol{x}}(t)=\boldsymbol{x}(t)-\hat{\boldsymbol{x}}(t)$

Based on Eq. (10), the error dynamics of the observer is represented as follows:

$$
\begin{aligned}
& \dot{\tilde{x}}_{1}(t)=\Delta f_{1}-k_{1} \operatorname{sign}\left(x_{1}-\hat{x}_{1}\right) \\
& \dot{\tilde{x}}_{2}(t)=\Delta f_{2}-k_{2} \operatorname{sign}\left(x_{1}-\hat{x}_{1}\right) \\
& \quad \vdots \\
& \dot{\tilde{x}}_{8}(t)=\Delta f_{8}-k_{8} \operatorname{sign}\left(x_{1}-\hat{x}_{1}\right)
\end{aligned}
$$

where 
$\Delta f_{i}=f_{i}(\boldsymbol{x}, u)-f_{i}(\hat{\boldsymbol{x}}, u), \quad i=1, \cdots, 8$.

Defining a sliding surface as:

$s(t)=x_{1}(t)-\hat{x}_{1}(t)=\tilde{x}_{1}(t)$

A sliding condition for $\tilde{x}_{1}$ is

$\frac{d}{d t}\left(\frac{1}{2} s^{2}\right)=s \dot{s} \leq-\eta|s| \quad$ or $\quad \dot{s}=-\eta \operatorname{sign}(s)$

Under the assumption that $\left|\Delta f_{i}\right| \leq F_{i}$, we can select $k_{i}$ to satisfy the sliding condition as:

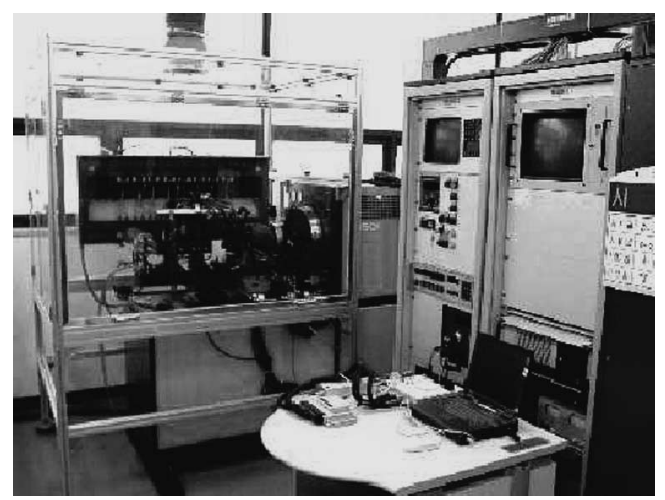

Fig. 7 Injector test bench
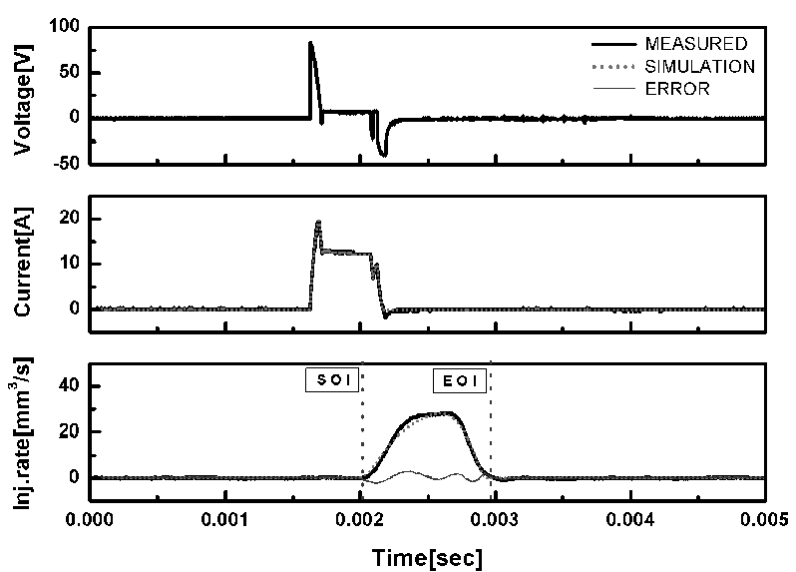

(a) Injection duration $=0.5 \mathrm{~ms}$
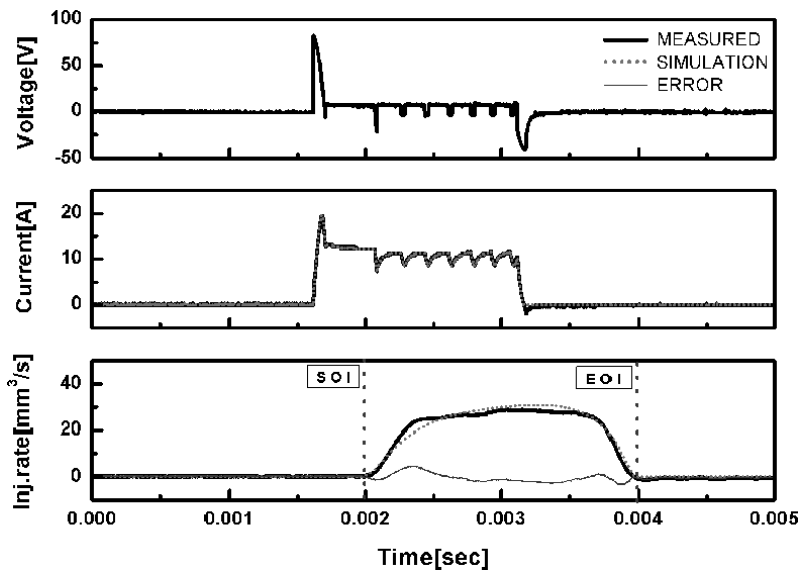

(b) Injection duration $=1.5 \mathrm{~ms}$

Fig. 8 Estimation of injection timing and injection rate for various injection durations (at rail pressure of 1200 bar)

$$
k_{i} \geq \eta_{i}+F_{i}, \quad i=1, \cdots, 8
$$

By this condition, $\tilde{x}_{1}$ reaches the sliding surface and the estimation error is converged to zero. If we choose the variables, in sequence, $k_{2}, \cdots, k_{8}$ to satisfy the conditions, it is possible to estimate state variables.

\section{Experiment}

\subsection{Experimental environment}

Figure 7 shows the injector test bench, data acquisition equipment, and injection rate meter. The injector test bench is designed to reproduce the conditions of the real common-rail injection system and modulate the rail pressure up to 1350 bar. In order to validate the developed injector model and the observer, the voltage, current, and injection rate signals are measured by a multifunction DAQ (data acquisition) board from National Instrument ${ }^{\circledR}$. The range of the rail pressure is from 700 to $1300 \mathrm{bar}$, and the injection duration is from 0.5 to $1.5 \mathrm{~ms}$.

\subsection{Experimental results}

In order to evaluate the proposed observer, the simulated results and the measured data are compared over a
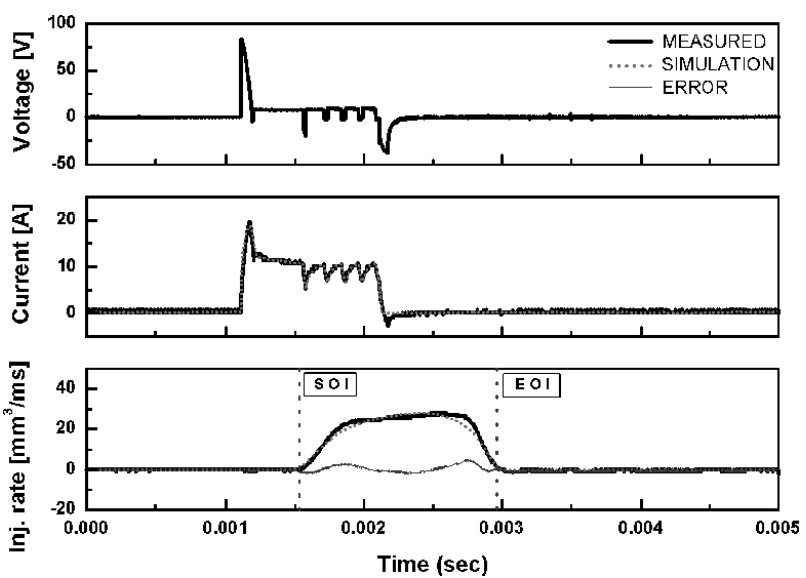

(a) Rail pressure $=1100$ bar
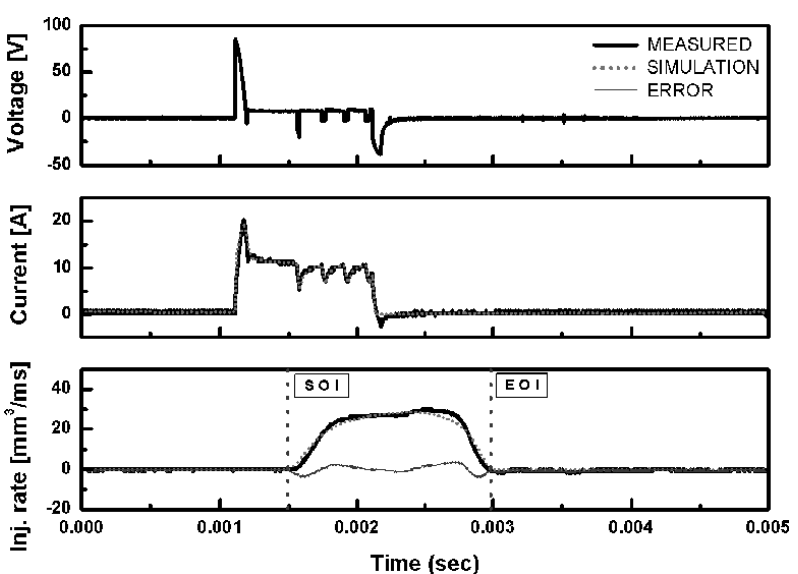

(b) Rail pressure $=1300$ bar

Fig. 9 Estimation of injection timing and injection rate for various injection pressures (at injection duration of $1.0 \mathrm{~ms}$ ) 

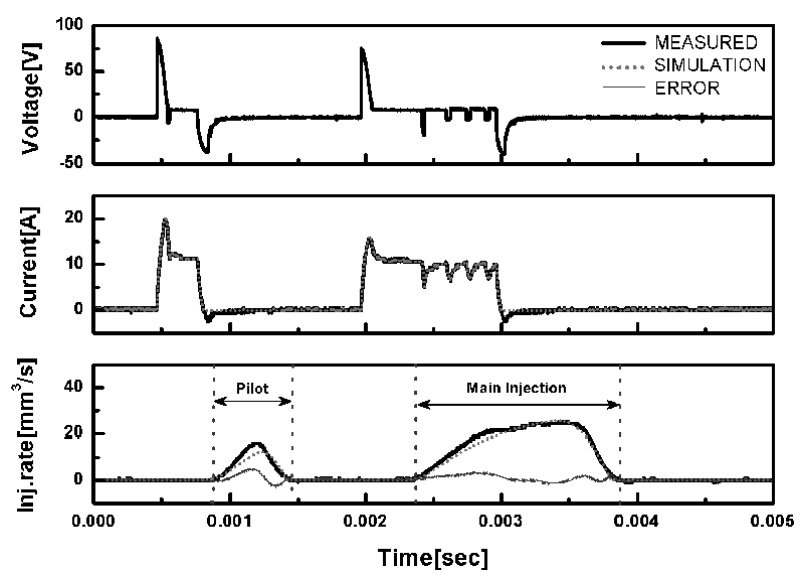

(a) Rail pressure $=900 \mathrm{bar}$
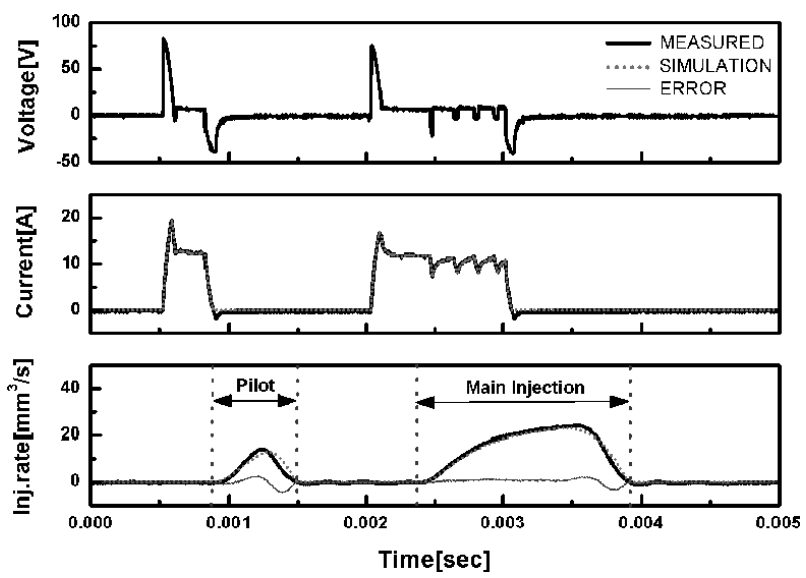

(b) Rail pressure $=1000$ bar

Fig. 10 Estimation of injection timing and injection rate for various pilot injection (at injection duration of $1.0 \mathrm{~ms}$ )

variety of operating points along with the variation of the injection duration and the common-rail pressure. Figure 8 represents the estimation of the injection rate for the injection duration of $0.5 \mathrm{~ms}$ and $1.5 \mathrm{~ms}$ at the rail pressure of 1200 bar. Figure 9 shows the estimation performance of the injection rate for the rail pressures of $1100 \mathrm{bar}$ and 1300 bar for an injection duration of $1.0 \mathrm{~ms}$. The behaviors of the solenoid current, injection timing, and injection rate are well described by the simulated profiles, as is clearly evident in Figs. 8 and 9. Also Fig. 10 demonstrates the estimated and measured results when a pilot injection is added ${ }^{(11)}$. The comparison study shows that the proposed observer estimates the injection timing and the injection rate of the common-rail injector effectively with only minor error.

\section{Conclusions}

The conclusion of this research can be summarized as follows:
1) A nonlinear mathematical model was developed to simulate the dynamic responses of a common-rail injector. This model was verified by the corresponding injection experiments.

2 ) A sliding mode observer based on the proposed model was introduced to overcome the model uncertainties.

3 ) Sliding mode observer for the estimations of the injection timing and the injection rate was designed.

4 ) The simulation and the experimental study reveals that the proposed observer can effectively estimate the injection timing and rate of the common-rail injector.

5 ) In conclusion, the potentiality of a sensorless feedback control scheme was exploited by the observer design of the injection timing and rate.

\section{References}

(1) Stumpp, G. and Ricco, M., Common Rail - An Attractive Fuel Injection System for Passenger Car DI Diesel Engines, SAE Paper No.960870 (1996).

( 2 ) Boehner, W. and Hummel, K., Common Rail Injection System for Commercial Diesel Vehicles, SAE Paper No.970345 (1997).

( 3 ) Guerrassi, N. and Dupraz, P., A Common Rail Injection System for High Speed Direct Injection Diesel Engines, SAE Paper No.980803 (1998).

( 4 ) Sunwoo, M., Yoon, P., Park, S. and Jin, J., A Study on the Electronic Control of HSDI Diesel Engines, Proc. of the 7th Next Generation Vehicle Workshop, (1999).

( 5 ) Hountalas, D.T. and Kouremenos, A.D., Development of a Fast and Simple Simulation Model for the Fuel Injection System of Diesel Engines, Advances in Engineering Software, Vol.29, No.1 (1998), pp.13-28.

( 6 ) Kano, H. and Kato, M., Contribution of Optimum Design for Nozzle Configuration to Spray Formation, SAE Paper No.900824 (1990).

( 7 ) Misawa, E.A. and Hedrick, J.K., Nonlinear Observers - A State-of-the-Art Survey, Journal of Dynamic Systems, Measurement, and Control, Vol.111 (1989).

( 8 ) Wang, G.B., Peng, S.S. and Huang, H.P., A Sliding Observer for Nonlinear Process Control, Chemical Engineering Science, Vol.52, No.5 (1997), pp.787-805.

( 9 ) Kao, M. and Moskwa, J.J., Engine Road and Equivalence Ratio Estimation for Control and Diagnostic via Nonlinear Sliding Observers, Int. J. of Vehicle Design, Vol.15 (1994).

(10) Slotine, J.E., Hedrick, J.K. and Misawa, E.A., On Sliding Observer for Nonlinear Systems, Journal of Dynamic Systems, Measurement, and Control, Vol.109 (1987).

(11) Henein, N.A. and Lai, M.C., Characteristics of a Common Rail Diesel Injection System under Pilot and Post Injection Modes, SAE Paper No.2002-01-0218 (2002). 